(C) 2018, American Psychological Association. This paper is not the copy of record and may not exactly replicate the final, authoritative version of the article. Please do not copy or cite without authors permission. The final article will be available, upon publication, via its DOI: 10.1037/xge0000497

RUNNING TITLE: SURPRISE-RELATED RESPONSE

Surprise as an explanation to auditory novelty distraction and post-error slowing

Fabrice B. R. Parmentier ${ }^{1,2,3}$

Martin R. Vasilev 4

$\&$

Pilar Andrés ${ }^{1,2}$

${ }^{1}$ Department of Psychology and Research Institute for Health Sciences (iUNICS), University of the Balearic Islands, Spain

2 Balearic Islands Health Research Institute (IdISBa), Spain 3 School of Psychology, University of Western Australia, Australia

${ }^{4}$ Department of Psychology, Bournemouth University, UK

Word count (including abstract but excluding references, figure captions, acknowledgments): 3944 words

Corresponding author:

Fabrice B. R. Parmentier

Department of Psychology

University of the Balearic Islands

07122 Palma de Mallorca

(Tel) ++34 971172750

(Fax) ++34 971172309

Email: fabrice.parmentier@uib.es 
Abstract

Performance in sustained attention tasks is known to be slowed by the occurrence of unexpected taskirrelevant distractors (novelty distraction) and the detection of errors (post-error slowing); two wellestablished phenomena studied separately and regarded as reflecting distinct underpinning mechanisms. We measured novelty distraction and post-error slowing in an auditory-visual oddball task to test the hypothesis that they both involve an orienting response. Our results confirm that the two effects exhibit a positive interaction. We show that a trial-by-trial measure of surprise credibly accounts for our empirical data. We suggest that novelty distraction and post-error slowing both reflect an orienting response to unexpected events and a reappraisal of action plans. 
Everyday efficient performance often requires the ability to adjust to distractors and modify our behavior when we make errors. This is illustrated by two well-established phenomena: novelty distraction and post-error slowing. Novelty distraction is defined as the detrimental effect of unexpected (novel) versus predictable (standard) task-irrelevant stimuli on ongoing task performance (e.g., Parmentier, 2014; Schröger, 1996), reflecting the involuntary capture of attention by the unexpected stimulus and the cost of the involuntary orienting of attention to and from that stimulus (e.g., Escera, Alho, Winkler, \& Näätänen, 1998; Parmentier, Elford, Escera, Andrés, \& Miguel, 2008; Schröger, 1996). Post-error slowing refers to the slowing of responses following the commission of an error relative to that of a correct response (Jentzsch \& Dudschig, 2009) and is thought to reflect an increase in cognitive control to minimize the risk of further errors (Botvinick, Braver, Barch, Carter, \& Cohen, 2001). At first sight, these phenomena appear to be distinct. Here we suggest that both phenomena might involve an orienting response.

\section{Novelty distraction}

A commonly used task to study novelty distraction is the oddball paradigm, in which participants perform a primary task while ignoring task-irrelevant sounds. The same sound is repeated on most trials (standard sound) while, on rare and unpredictable trials, this sound is replaced by a novel one. Electrophysiological studies show that unexpected sounds trigger three specific responses: mismatch negativity (MMN), P3a and reorientation negativity or RON (e.g., Berti, 2008; Escera et al., 1998; Horvath, Winkler, \& Bendixen, 2008; Schröger, 1996; Schröger, Giard, \& Wolff, 2000; Schröger, Marzecová, \& SanMiguel, 2015; Schröger \& Wolff, 1998). These responses reflect, respectively, the detection of auditory change, the involuntary orienting of attention towards the unexpected sound, and a re-orienting of attention toward the ongoing primary task (e.g., Berti, 2008; Berti \& Schröger, 2001). Unexpected sounds lengthen response times to targets and, sometimes, reduce response accuracy (e.g., Parmentier, 2014; Schröger, 1996). This effect is interpreted as the result of the shift of attention to, and away from, the unexpected sound (e.g., Escera et al., 1998; Parmentier et al., 2008; 
Schröger, 1996), which can involve the involuntary semantic analysis of this sound (e.g., Escera, Yago, Corral, Corbera, \& Nuñez, 2003; Parmentier \& Kefauver, 2015; Parmentier, Pacheco-Unguetti, \& Valero, 2018; Parmentier, Turner, \& Perez, 2014; Parmentier, Turner, \& Elsley, 2011; Roye, Jacobsen, \& Schröger, 2007, 2013; Shtyrov, Hauk, \& Pulvermuller, 2004; Wetzel, Widmann, \& Schröger, 2011), and emanates from the novel sounds' violation of the cognitive system's predictions rather than from their low probability of occurrence (e.g., Parmentier, Elsley, Andrés, \& Barceló, 2011; Schröger, Bendixen, Trujillo-Barreto, \& Roeber, 2007). Hence, novelty distraction reduces or vanishes when unexpected sounds are predictable, explicitly (e.g., Horváth \& Bendixen, 2012; Parmentier \& Hebrero, 2013; Sussman, Winkler, \& Schröger, 2003) or implicitly (e.g., Parmentier, Elsley, et al., 2011; Schröger et al., 2007). The fundamental nature of novelty distraction is illustrated by its observation across a large range of tasks and stimuli types: visual and auditory categorization tasks, two-alternative forcedchoice tasks, go-nogo tasks, visual matching tasks, or serial recall tasks, regardless of whether relevant and irrelevant stimulus features form a single perceptual object or are temporally and perceptually decoupled, and regardless of whether irrelevant and relevant stimuli are presented within the same modality or across modalities (Bendixen et al., 2010; Berti \& Schröger, 2001; Hughes, Vachon, \& Jones, 2005; Li, Parmentier, \& Zhang, 2013; Ljungberg \& Parmentier, 2012; Ljungberg, Parmentier, Leiva, \& Vega, 2012; Parmentier, 2014; Röer, Bell, Körner, \& Buchner, 2018; Röer, Bell, Marsh, \& Buchner, 2015).

While attentional orienting plays a role in novelty distraction, recent evidence points out that novel sounds may also induce some form of behavioral adjustment. Indeed, such sounds appear to yield a temporary inhibition of motor regions (e.g., Wessel, 2017; Wessel et al., 2016; Wessel \& Aron, 2013), and hinder response repetition (Roeber, Berti, Widmann, \& Schröger, 2005). Furthermore, Parmentier (2016) found that unexpected sounds slow responses when an action plan is repeated from the previous trial but facilitate performance when they help disengage from a state of behavioral inaction. Hence, there is evidence of both attention orienting and adaptive control in deviance distraction. 


\section{Post-error slowing}

Since Rabbitt's (Rabbitt, 1966) early report, post-error slowing has been abundantly observed in a variety of tasks such as categorization (e.g., Jentzsch \& Dudschig, 2009), Flanker (Danielmeier \& Ullsperger, 2011; Fischer, Danielmeier, Villringer, Klein, \& Ullsperger, 2016), Stroop (e.g., Gehring \& Fencsik, 2001), or Simon (e.g., King, Korb, von Cramon, \& Ullsperger, 2010) tasks.

Post-error slowing is widely regarded as evidence of adaptive control, whether as a way to promote more controlled responding (Ridderinkhof, 2002), as a delay allowing the engagement of attentional top-down modulation (MacDonald, Cohen, Stenger, \& Carter, 2000), or as the result of decreased activity in response priming units (Botvinick et al., 2001; King et al., 2010).

However, some evidence suggests that post-error slowing may also reflect an orienting response to errors. In an elegant study, Notebaert, Houtman, Van Opstal, Gevers, Fias and Verguts (2009) varied task difficulty to manipulate the frequency of errors and found post-error slowing when errors were rare, but post-correct slowing when errors were the most likely outcome (see also Núñez Castellar, Kühn, Fias, \& Notebaert, 2010). In addition, errors and novel visual stimuli were found to yield common neuroanatomical activity (Wessel, Danielmeier, Morton, \& Ullsperger, 2012).

\section{Novelty distraction and post-error slowing as products of an orienting response}

Following the steps of Notebart et al. (2009), we suggest that deviance distraction and post-error slowing may be instances of a more fundamental phenomenon: the orienting response. Under this hypothesis, participants' attention is captured by unexpected events, whether these are novel taskirrelevant stimuli or the production of errors (in a context in which most responses are correct), which trigger an involuntary orienting of attention toward such events. We tested this hypothesis in a crossmodal oddball task in which participants categorized visual digits as odd or even while ignoring rare and unexpected changes in a stream of task-irrelevant sounds. If deviance distraction and post-error slowing are underpinned by a common orienting mechanism, these two effects should interact such 
that response times should increase with the amount of surprise conveyed by the context in which participants perform the primary task. Novel sounds following the production of an error should constitute the most surprising context and therefore yield the worse performance. In contrast, standard sounds and correct responses being both highly probable, their combined occurrence should be highly predictable (i.e., not surprising) and performance should be best in that context. In other words, the orienting response hypothesis predicts a pattern of interaction by which post-error slowing and deviance distraction should amplify each other. In contrast, if deviance distraction and post-error slowing are underpinned by distinct mechanisms occurring serially, no interaction should be observed (instead, additive effects should be observed). Alternatively, if one assumes that both effects are independent but occur in parallel, performance should be determined by the largest of the two effects (for example, responses should be as slow as the slowest of the two effects, leading to a levelling-off of performance in that condition). In that case, an interaction should be observed whereby one effect caps the other (in contrast with our prediction that the two effects share an orienting response mechanism and amplify each other).

Because we predicted a clear interaction between novelty distraction and post-error slowing (whereby the two effects amplify each other), we hypothesized a medium effect size $\left(\mathrm{d}_{z}=.5\right)$. A power analysis revealed that for a Type I error of .05 , a power of .95 , and an effect size of $.5\left(\mathrm{~d}_{z}\right)$ for a onetailed effect, the required sample size was 45 . To be safe, we recruited 100 participants.

\section{Method}

\section{Participants}


One hundred (69 females) undergraduate psychology students from the University of Plymouth volunteered to take part in this experiment. Participants were between 18 and 29 years of age $(M=$ $20.60, S D=2.21)$. All participants reported correct or corrected-to-normal vision and normal hearing.

\section{$\underline{\text { Stimuli, design and procedure }}$}

Participants completed 4 blocks of 168 trials each (8 practice trials followed by 160 test trials). In each trial, participants categorized a visual digit (1-8) as odd or even while ignoring an irrelevant sound presented shortly before that digit. Each trial consisted of the following sequence of events. A white fixation cross appeared at the center of the black screen and was followed, 100ms later, by the presentation of an irrelevant sound lasting $150 \mathrm{~ms}$. A temporal gap of $50 \mathrm{~ms}$ separated the sound's offset from the onset of a target digit (presented in white), which replaced the fixation cross. The digit remained on the screen for $150 \mathrm{~ms}$, before being replaced by the fixation cross during an interval of $800 \mathrm{~ms}$. Participants therefore had a total response window of $950 \mathrm{~ms}$. At the end of this interval, the next trial started automatically (one trial blending into the next without any visible or audible separation). The visual digits and the fixation cross sustained an approximate angle of 2.6 degrees (participants sitting approximately $50 \mathrm{~cm}$ away from the screen). Participants used the keyboard keys $\mathrm{Z}$ and $\mathrm{X}$ to respond using two fingers of their dominant hand. The mapping between the response keys and the odd/even responses was counterbalanced across participants.

Two sound conditions were compared within each block. In the standard condition $(75 \%$ of trials), the sound was a $600 \mathrm{~Hz}$ sinewave tone lasting $150 \mathrm{~ms}$ (including $10 \mathrm{~ms}$ of rise/fall times). In the novel condition (25\% of trials), we used 60 different environmental sounds taken from Andrés, Parmentier \& Escera (2006). These sounds had a 150ms duration (including 10ms rise/fall times), were digitally recorded, and low-pass filtered at 10,000 Hz. They were randomly sampled and no novel sound was used more than three times across the experiment. All sounds were normalized and presented binaurally through headphones at approximately $75 \mathrm{~dB}$ SPL. The first 8 trials of each block contained only standard sounds, were treated as warm-up practice trials, and were not included in 
the data analysis. A different quasi-random order of presentation of the standard and novel trials was used for every participant, with the constraint that novel trials never occurred on consecutive trials. Target digits (1-8) were used equally often across the task, and in equal proportions in the standard and novel trials.

Participants were tested individually in a quiet room. They were instructed to focus on the digit categorization task and to ignore the irrelevant sounds. Instructions emphasized the need for both speed and accuracy. This study adhered to the ethical standards of the British Psychological Society and the American Psychological Association, and received ethical approval from the Ethics Committee of the University of Plymouth, where the study was carried out.

\section{Results}

The mean proportion of correct responses and mean response times for correct responses (measured from the onset of the visual targets) were analyzed as a function of the type of sound condition (standard vs. novel) and whether the previous trial yielded a correct response or an error. Two participants were removed from the analysis because they failed to follow the task instructions and their performance was at chance level.

Mean response times (illustrated in Figure 1, left panel) were significantly longer in novel compared to standard trials $\left[F(1,97)=53.077, M S E=1693, p<.001, \eta_{p}^{2}=0.354\right]$, and following errors compared to correct responses $\left[F(1,97)=41.133, M S E=2227, p<.001, \eta_{p}^{2}=0.298\right]$. A significant interaction was found between these factors $\left[F(1,97)=13.554, M S E=1574, p<.001, \eta_{p}^{2}=0.123\right]$, reflecting the greater difference between novel and standard trials following errors compared to correct responses.

The proportion of correct responses (illustrated in Figure 1, right panel) was greater in standard than in novel trials $\left[F(1,97)=7.188, M S E=0.0052, p=.009, \eta_{p}^{2}=0.069\right]$, and lower after errors 
than correct responses $\left[F(1,97)=26.556, M S E=0.0112, p<.001, \eta_{p}^{2}=0.215\right]$. These two factors interacted $\left[F(1,97)=4.231, M S E=0.0046, p=.042, \eta_{p}^{2}=0.042\right]$, reflecting greater detrimental effect of novel compared to standard sounds in post-error trials (i.e., the two effects amplified each other).

- - - Insert Figure 1 about here - - -

\section{Killing two birds with one stone using a measure of surprise}

As reported in the previous section, novelty distraction and post-error slowing interacted. To assay the hypothesis that these phenomena may reflect a common orienting response, we sought to determine whether our participants' response times and response accuracy (and more specifically the interaction between deviance distraction and post-error slowing) could be adequately explained using a measure of contextual surprise.

We measured surprise in each of the four trial contexts encountered in the task: standard sound following a correct response (post-correct standard), standard sound following an error (posterror standard), novel sound following a correct response (post-correct novel), and novel sound following an error (post-error novel). The level of surprise was measured in these four contexts on a trial-to-trial basis and for each participant using a Bayesian algorithm comparing the posterior probability of a given context (i.e., the probability of that event on all trials up to and including the current trial) against the prior probability of that event (i.e., the probability of that event on all trials up to but excluding the current trial) by way of the Kullback-Leibler divergence formula (Wessel et al., 2016):

$$
S_{i}=\log _{2}\left(\frac{p_{\text {context }}(1 \ldots i)}{p_{\text {context }}(1 \ldots i-1)}\right)
$$


Thus, Surprise (S) was calculated for each trial $i$ based on the ratio of the prior probability of the context encountered in that trial against the updated probability (i.e., including the current trial) of that context. A 2 (type of sound: novel vs. standard) x 2 (type of trial: post-correct vs. post-error) ANOVA for repeated measures carried out on $S$ confirmed that novel sounds yielded more surprise than standard sound $\left[F(1,97)=280.309, M S E=0.02349, p<.001, \eta_{p}^{2}=0.743\right]$, and that errors yielded more surprise than correct responses $\left[F(1,97)=227.070, M S E=0.00861, p<.001, \eta_{p}^{2}=0.701\right] . \mathrm{A}$ significant interaction between these factors was also observed $[F(1,97)=597.114, M S E=0.00686, p<$ $\left..001, \eta_{p}^{2}=0.860\right]$, as depicted in Figure 2 .

\section{- - - Insert Figure 2 about here - - -}

To gauge the extent to which S accounts for our participants' performance, we measured the mean RT and mean proportion of correct response for each participant in each of the four trial contexts described in the previous paragraph (total of 392 data points for each dependent variable: RTs and proportion correct) and analyzed this data with Linear Mixed Models (LMMs) using the lme4 package v.1.1-12 (Bates, Machler, Bolker, \& Walker, 2014) in R 3.5.1 (R Core Team, 2016). Surprise was entered as a fixed effect in the model. Random intercept and random slopes for Surprise were added to participants. Results were considered statistically significant for $t$ values $\geq 1.96$. As visible in Table 1, Surprise had a significant effect on both dependent variables.

$$
\text { - - - Insert Table } 1 \text { about here - - - }
$$

In order to determine how our model based on Surprise compared to the 2-factorial model (post-error slowing, novelty distraction, and their interaction), we regressed the empirical data onto the fitted data of the Surprise and 2-factorial models (in separate regression analyses for the RT and 
proportion correct data). These fitted data were produced using linear mixed models. The Surprise model was that described in the previous paragraph. The 2-factorial model included the following factors (fixed effects): type of sound (novel vs. standard), type of trial (post-correct vs. post-error), and the interaction of these two factors. Random intercept and random slopes for the type of trial and type of sound were added to participants. This method allowed us to compare how close the Surprise and 2-factorial models came to the empirical data. The regression model accounted for a sizable proportion of the empirical RT variance, $R^{2}=.949, F(2,389)=3631.317, p<.001$. The Surprise model significantly predicted empirical RTs $[B=1.011, t(389)=16.338, p<.001,95 \%$ CI: 0.889 to 1.133$]$, while the 2 -factorial did not $[B=0.037, t(389)=0.568, p=.570,95 \%$ CI: -.091 to .650]. To assess the unique variance accounted by each of our two predictors, we compared regression models with one predictor versus both predictors (see Parmentier, Elford, \& Maybery, 2005). The results of this analysis, presented in Table 2 (top panel), revealed that while the Surprise model made a significant unique contribution to the model fit, the 2-factorial model did not.

\section{- - - Insert Table 2 about here - - -}

The analysis of the proportion of correct responses showed that the Surprise and 2-factorial models accounted for a significant proportion of the variance in the empirical data $\left(R^{2}=.888, F(2,389)\right.$ $=1544.678, p<.001)$. Surprise predicted significantly empirical response accuracy $[B=1.326, t(389)=$ 22.856, $p<.001,95 \%$ CI: 1.212 to 1.440$]$, as did the 2-factorial model $[B=-.269, t(389)=-4.124, p<.001$, 95\% CI: -0.397 to -0.141$]$. Comparisons of regression models including either one or both predictors showed that both Surprise and the 2-factorial model accounted for a significant and unique proportion of the variance in RTs. This suggests that Surprise does not capture all of the variance explained by the 2-factorial model. Overall, both models fitted the data well (see Figure 3 for a graphical illustration), but the $\mathrm{R}^{2}$ values were somewhat larger for the Surprise model than for the 2factorial model. 


\section{- - - Insert Figure 3 about here - - -}

While the data points presented in Figure 3 form visible clusters, some individual data points appear to depart from the rest (four observed RT data points are visibly longer than the rest, and six observed proportions of correct responses are visibly lower than the remaining data points). To ensure that these conspicuous data points did not unduly influence our results, we repeated the analyses without them. The results from these complementary analyses are similar to our initial findings (see the Appendix). These results confirmed that the Surprise model fitted the empirical data at least as well as the 2-factorial model. Interestingly, the comparison of Table 2 and Table A1 (see the Appendix) does suggest that the fitted data calculated using the data set including the more extreme data points benefited the Surprise model. Indeed, the proportion of variance uniquely explained by the Surprise model (the change in $\mathrm{R}^{2}$ ) was numerically smaller when excluding these data points (while the reverse was observed for the unique proportion of variance explained by the 2 -factorial model).

Overall, surprise offered as good of a fit for the observed data as the 2-factorial model. This may in part reflect the fact that surprise was calculated on a trial-to-trial basis, thereby potentially providing richer information than the 2-factorial model (which reflects factors that did not vary across the experiment). It is also worth mentioning that the Surprise model used a single factor (S) while the 2-factorial model used three (type of trial, type of sound, and the interaction between these factors). Hence, overall, the Surprise model arguably provides a parsimonious account of our empirical findings because it requires fewer predictors to explain the data. In any case, the key conclusion is that surprise offers a credible account of our empirical data.

\section{Discussion}

We set out to test the hypothesis that novelty distraction and post-error slowing may involve a common mechanism: an orienting response. Our results confirmed that participants performing a 
sustained attention task are slower (and less accurate) following the presentation of a sound violating sensory predictions, and slower following the commission of an error. These two effects amplified each other. Both effects and their interaction were convincingly accounted for by a measure of surprise, which was calculated based on a context integrating both irrelevant stimuli (task-irrelevant sounds) and behavioral outcomes (performance on the previous trial).

Traditionally, novelty distraction has been thought to reflect the cost of the involuntary orienting of attention to, and re-orienting from, unexpected stimuli (e.g., Escera et al., 1998; Parmentier, 2014; Schröger, 1996), while post-error slowing has been viewed as the signature of behavioral control aiming to optimize behavior (e.g., Li et al., 2008). However, recent findings also suggest a role for attentional reorienting in post-error slowing (Notebaert et al., 2009) and of action control in deviance distraction (e.g., Parmentier, 2016; Wessel, 2017; Wessel \& Aron, 2013). Interestingly, early on, Laming (1968) envisaged post-error slowing as the result of a bias against the response that just elicited the error, which echoes with the tendency of unexpected sounds to hinder the repetition of a response (Roeber et al., 2005) or an action plan (e.g., Parmentier, 2016; Wessel \& Aron, 2013). Hence, we would argue that attentional orienting and action control are not mutually exclusive and may be at play in both effects. Such a notion overcomes the tendency to seek separate explanations to apparently distinct phenomena and recasts these in the more general arena of adaptive behavior and the intimate connection between perception and action. While this link has somewhat been overlooked since the ascent of cognitivism and its focus on "information processing", it is interesting to note that it was an inherent part of early theories of the orienting response. In fact, Pavlov (1927) initially talked about a "novelty reflex". The momentary slowing of our behavior may be viewed as "distraction" in the context of a psychology experiment, but it is a mechanism through which an organism interrupts ongoing behavior, orients its receptor organs toward the source of change in the immediate environment and enhances its probability of selecting the most appropriate plan for action. Not only does our behavior adapt to the detection of change and the orienting of our attention to its source, our attention also orients towards unexpected consequences of our behavior, 
for example when the sensory consequence of our actions violate our predictions (Schröger et al., 2015). In our view, the orienting response may be regarded as the observable facet of an ensemble of sensory-motor mechanisms aimed at promoting adaptive behavior in the face of an unexpected contextual change.

One limitation of our study is that the production of errors was not a factor that was manipulated by the experimenter. While inherent to studies of post-error slowing, this aspect may still be relevant when interpreting our data. Indeed, as one reviewer suggested, errors may be the result of phasic fluctuations of attention. Assuming that such fluctuations may span over successive trials and simultaneously increase the likelihood of errors and slow cognitive processes, it cannot be ruled out that a transient reduction in phasic attention may contribute to the production of an error on trial $t$ and, if an unexpected sound is presented on trial $t+1$, slow the resulting orienting response. Such a proposition does not rule out a role for surprise, but it does not rule it in either. To address this issue in future studies, it may be interesting to measure post-error slowing and deviance distraction while tracking some independent index of sustained attention. This could be achieved by measuring EEG spectral activity, as previous work indicates that attenuations of alertness and decrements in cognitive performance are associated with increases in beta and theta rhythms (e.g., Clayton, Yeung, \& Cohen Kadosh, 2015; De Gennaro et al., 2007; Makeig \& Jung, 1995). It should be pointed out, however, that fluctuations in phasic attention cannot account for other indications of a role of the orienting response in post-stimulus slowing: the demonstration of post-correct slowing when errors (instead of correct responses) are the least expected outcome (Notebaert et al., 2009; Núñez Castellar et al., 2010), or the report of a common neural architecture for the processing of both errors and novel stimuli (Wessel et al., 2012).

In conclusion, we propose that unexpected contextual changes capture attention, trigger an orienting response and hinder the repetition of behavior in order to allow an adaptive reappraisal of action plans. We propose that contextual changes encompass sensory stimulation (e.g., novel sounds) 
as well as one's own behavior (e.g., errors), and that the surprising value of this contextual change may account in part for novelty distraction, post-error slowing, and their interaction. 


\section{Context of the research}

The work reported here is part of a larger project seeking to study novelty distraction from its fundamental cognitive underpinnings to its connection with more general factors such as aging (e.g., Leiva, Andrés, \& Parmentier, 2015; Leiva, Andrés, Servera, Verbruggen, \& Parmentier, 2016), the participants' emotional state (Pacheco-Unguetti \& Parmentier, 2014, 2016), or other cognitive phenomena (such as post-error slowing or interference effects). Our wider theoretical thesis is that unexpected stimuli call upon our attention when they violate the cognitive system's predictions, which are themselves a by-product of the system's simplified model of the world around us (model that allows the compression of large amounts of information into patterns, reducing energy consumption and enabling faster and more consistent behavior). 


\section{References}

Andrés, P., Parmentier, F. B. R., \& Escera, C. (2006). The effect of age on involuntary capture of attention by irrelevant sounds: A test of the frontal hypothesis of aging. Neuropsychologia, 44(12), 2564-2568. https://doi.org/10.1016/j.neuropsychologia.2006.05.005

Bates, D. M., Machler, M., Bolker, B. M., \& Walker, S. C. (2014). Fitting linear mixed-effects models using lme4. Journal of Statistical Software, 67(1), 1-48. https://doi.org/10.18637/jss.v067.i01

Bendixen, A., Grimm, S., Deouell, L. Y., Wetzel, N., Maedebach, A., \& Schröger, E. (2010). The timecourse of auditory and visual distraction effects in a new crossmodal paradigm.

Neuropsychologia, 48(7), 2130-2139. https://doi.org/10.1016/j.neuropsychologia.2010.04.004

Berti, S. (2008). Cognitive control after distraction: Event-related brain potentials (ERPs) dissociate between different processes of attentional allocation. Psychophysiology, 45(4), 608-620. https://doi.org/10.1111/j.1469-8986.2008.00660.x

Berti, S., \& Schröger, E. (2001). A comparison of auditory and visual distraction effects: behavioral and event-related indices. Brain Research. Cognitive Brain Research, 10(3), 265-273.

Botvinick, M., Braver, T. S., Barch, D. M., Carter, C. S., \& Cohen, J. D. (2001). Conflict monitoring and cognitive control. Psychological Review, 108(3), 624-652. https://doi.org/10.1037//0033295x.108.3.624

Clayton, M. S., Yeung, N., \& Cohen Kadosh, R. (2015, April 1). The roles of cortical oscillations in sustained attention. Trends in Cognitive Sciences, 19(4), 188-195.

https://doi.org/10.1016/j.tics.2015.02.004

Danielmeier, C., \& Ullsperger, M. (2011). Post-error adjustments. Frontiers in Psychology, 2(SEP), 1-10. https://doi.org/10.3389/fpsyg.2011.00233

De Gennaro, L., Marzano, C., Veniero, D., Moroni, F., Fratello, F., Curcio, G., ... Rossini, P. M. (2007). Neurophysiological correlates of sleepiness: A combined TMS and EEG study. NeuroImage, 36(4), 1277-1287. https://doi.org/10.1016/j.neuroimage.2007.04.013

Escera, C., Alho, K., Winkler, I., \& Näätänen, R. (1998). Neural mechanisms of involuntary attention to 
acoustic novelty and change. Journal of Cognitive Neuroscience, 10(5), 590-604.

https://doi.org/10.1162/089892998562997

Escera, C., Yago, E., Corral, M. J., Corbera, S., \& Nuñez, M. I. (2003). Attention capture by auditory significant stimuli: Semantic analysis follows attention switching. European Journal of Neuroscience, 18(8), 2408-2412. https://doi.org/10.1046/j.1460-9568.2003.02937.x

Fischer, A. G., Danielmeier, C., Villringer, A., Klein, T. A., \& Ullsperger, M. (2016). Gender Influences on Brain Responses to Errors and Post-Error Adjustments. Scientific Reports, 6(1), 24435. https://doi.org/10.1038/srep24435

Gehring, W. J., \& Fencsik, D. E. (2001). Functions of the medial frontal cortex in the processing of conflict and errors. The Journal of Neuroscience, 21(23), 9430-9437.

https://doi.org/10.1523/JNEUROSCI.21-23-09430.2001

Horváth, J., \& Bendixen, A. (2012). Preventing distraction by probabilistic cueing. International Journal of Psychophysiology, 83(3), 342-347. https://doi.org/10.1016/j.ijpsycho.2011.11.019

Horvath, J., Winkler, I., \& Bendixen, A. (2008). Do N1/MMN, P3a, and RON form a strongly coupled chain reflecting the three stages of auditory distraction? Biological Psychology, 79(2), 139-147. https://doi.org/10.1016/j.biopsycho.2008.04.001

Hughes, R. W., Vachon, F., \& Jones, D. M. (2005). Auditory attentional capture during serial recall: Violations at encoding of an algorithm-based neural model? Journal of Experimental PsychologyLearning Memory and Cognition, 31(4), 736-749. https://doi.org/10.1037/0278-7393.31.4.736

Jarmasz, J., \& Hollands, J. G. (2009). Confidence Intervals in Repeated-Measures Designs: The Number of Observations Principle. Canadian Journal of Experimental Psychology, 63(2), 124-138. https://doi.org/10.1037/a0014164

Jentzsch, I., \& Dudschig, C. (2009). Why do we slow down after an error? Mechanisms underlying the effects of posterror slowing. Quarterly Journal of Experimental Psychology, 62(2), 209-218. https://doi.org/10.1080/17470210802240655

King, J. A., Korb, F. M., von Cramon, D. Y., \& Ullsperger, M. (2010). Post-error behavioral adjustments 
are facilitated by activation and suppression of task-relevant and task-irrelevant information processing. Journal of Neuroscience, 30(38), 12759-12769.

https://doi.org/10.1523/JNEUROSCI.3274-10.2010

Laming, D. (1968). Information theory of choice reaction times. London: Academic Press.

Leiva, A., Andrés, P., \& Parmentier, F. B. R. (2015). When Aging Does Not Increase Distraction: Evidence From Pure Auditory and Visual Oddball Tasks. Journal of Experimental PsychologyHuman Perception and Performance, 41(6), 1612-1621. https://doi.org/10.1037/xhp0000112

Leiva, A., Andrés, P., Servera, M., Verbruggen, F., \& Parmentier, F. B. R. (2016). The Role of Age, Working Memory, and Response Inhibition in Deviance Distraction: A Cross-Sectional Study. Developmental Psychology, 52(9), 1381-1393. https://doi.org/10.1037/dev0000163

Li, B., Parmentier, F. B. R., \& Zhang, M. (2013). Behavioral distraction by auditory deviance is mediated by the sound's informational value: Evidence from an auditory discrimination task. Experimental Psychology, 60(4), 260-268. https://doi.org/10.1027/1618-3169/a000196

Li, C. R., Huang, C., Yan, P., Paliwal, P., Constable, R. T., \& Sinha, R. (2008). Neural correlates of posterror slowing during a stop signal task: A functional magnetic resonance imaging study. Journal of Cognitive Neuroscience, 20(6), 1021-1029. https://doi.org/10.1162/jocn.2008.20071

Ljungberg, J. K., \& Parmentier, F. B. R. (2012). Cross-modal distraction by deviance: Functional similarities between the auditory and tactile modalities. Experimental Psychology, 59(6). https://doi.org/10.1027/1618-3169/a000164

Ljungberg, J. K., Parmentier, F. B. R., Leiva, A., \& Vega, N. (2012). The informational constraints of behavioral distraction by unexpected sounds: The role of event information. Journal of Experimental Psychology: Learning Memory and Cognition, 38(5), 1461-1468. https://doi.org/10.1037/a0028149

MacDonald, A. W., Cohen, J. D., Stenger, V. A., \& Carter, C. S. (2000). Dissociating the role of the dorsolateral prefrontal and anterior cingulate cortex in cognitive control. Science, 288(5472), 1835-1838. https://doi.org/10.1126/science.288.5472.1835 
Makeig, S., \& Jung, T. P. (1995). Changes in alertness are a principal component of variance in the EEG spectrum. NeuroReport, 7(1), 213-216. https://doi.org/10.1097/00001756-199512000-00051

Notebaert, W., Houtman, F., Van Opstal, F., Gevers, W., Fias, W., \& Verguts, T. (2009). Post-error slowing: An orienting account. Cognition, 111(2), 275-279.

https://doi.org/10.1016/j.cognition.2009.02.002

Núñez Castellar, E. P., Kühn, S., Fias, W., \& Notebaert, W. (2010). Outcome expectancy and not accuracy determines posterror slowing: ERP support. Cognitive, Affective and Behavioral Neuroscience, 10(2), 270-278. https://doi.org/10.3758/CABN.10.2.270

Pacheco-Unguetti, A. P., \& Parmentier, F. B. R. (2014). Sadness increases distraction by auditory deviant stimuli. Emotion, 14(1), 203-13. https://doi.org/10.1037/a0034289

Pacheco-Unguetti, A. P., \& Parmentier, F. B. R. (2016). Happiness increases distraction by auditory deviant stimuli. British Journal of Psychology, 107(3), 419-433. https://doi.org/10.1111/bjop.12148

Parmentier, F. B. R. (2014). The cognitive determinants of behavioral distraction by deviant auditory stimuli: A review. Psychological Research. https://doi.org/10.1007/s00426-013-0534-4

Parmentier, F. B. R. (2016). Deviant Sounds Yield Distraction Irrespective of the Sounds' Informational Value. Journal of Experimental Psychology-Human Perception and Performance, 42(6), 837-846. https://doi.org/10.1037/xhp0000195

Parmentier, F. B. R., Elford, G., Escera, C., Andrés, P., \& Miguel, I. S. (2008). The cognitive locus of distraction by acoustic novelty in the cross-modal oddball task. Cognition, 106(1), 408-432. https://doi.org/10.1016/j.cognition.2007.03.008

Parmentier, F. B. R., Elford, G., \& Maybery, M. (2005). Transitional information in spatial serial memory: Path characteristics affect recall performance. Journal of Experimental PsychologyLearning Memory and Cognition, 31(3), 412-427. https://doi.org/10.1037/0278-7393.31.3.412

Parmentier, F. B. R., Elsley, J. V., Andrés, P., \& Barceló, F. (2011). Why are auditory novels distracting? Contrasting the roles of novelty, violation of expectation and stimulus change. Cognition, 119(3), $374-380$. 
Parmentier, F. B. R., \& Hebrero, M. (2013). Cognitive control of involuntary distraction by deviant sounds. Journal of Experimental Psychology: Learning, Memory, and Cognition, 39(5), 1635-41. Retrieved from http://www.ncbi.nlm.nih.gov/pubmed/23565784

Parmentier, F. B. R., \& Kefauver, M. (2015). The semantic aftermath of distraction by deviant sounds: Crosstalk interference is mediated by the predictability of semantic congruency. Brain Research, 1626, 247-257. https://doi.org/10.1016/j.brainres.2015.01.034

Parmentier, F. B. R., Pacheco-Unguetti, A. P., \& Valero, S. (2018). Food words distract the hungry: Evidence of involuntary semantic processing of task-irrelevant but biologically-relevant unexpected auditory words. PLOS ONE, 13(1), e0190644.

https://doi.org/10.1371/journal.pone.0190644

Parmentier, F. B. R., Turner, J., \& Elsley, J. V. (2011). Distraction by auditory novelty: The course and aftermath of novelty and semantic effects. Experimental Psychology, 58(2), 92-101.

Parmentier, F. B. R., Turner, J., \& Perez, L. (2014). A dual contribution to the involuntary semantic processing of unexpected spoken words. Journal of Experimental Psychology. General, 143(1), 3845.

Pavlov, I. P. (1927). Conditioned reflexes. Oxford, UK: Oxford University Press.

R Core Team. (2016). R: A language and environment for statistical computing. Vienna, Austria. Retrieved from http://www.r-project.org

Rabbitt, P. M. A. (1966). Errors and error correction in choice-response tasks. Experimental Psychology, 71(2), 264-272. https://doi.org/10.1037/h0022853

Ridderinkhof, K. R. (2002). Micro- and macro-adjustments of task set: Activation and suppression in conflict tasks. Psychological Research, 66(4), 312-323. https://doi.org/10.1007/s00426-002-0104-7

Roeber, U., Berti, S., Widmann, A., \& Schröger, E. (2005). Response repetition vs. response change modulates behavioral and electrophysiological effects of distraction. Cognitive Brain Research, 22(3), 451-456. https://doi.org/10.1016/j.cogbrainres.2004.10.001

Röer, J. P., Bell, R., Körner, U., \& Buchner, A. (2018). Equivalent auditory distraction in children and 
adults. Journal of Experimental Child Psychology, 172, 41-58.

https://doi.org/10.1016/j.jecp.2018.02.005

Röer, J. P., Bell, R., Marsh, J. E., \& Buchner, A. (2015). Age equivalence in auditory distraction by changing and deviant speech sounds. Psychology and Aging, 30(4), 849-855.

https://doi.org/10.1037/pag0000055

Roye, A., Jacobsen, T., \& Schröger, E. (2007). Personal significance is encoded automatically by the human brain: an event-related potential study with ringtones. European Journal of Neuroscience, 26(3), 784-790. https://doi.org/10.1111/j.1460-9568.2007.05685.x

Roye, A., Jacobsen, T., \& Schröger, E. (2013). Discrimination of personally significant from nonsignificant sounds: A training study. Cognitive, Affective and Behavioral Neuroscience, 13(4), 930-943. https://doi.org/10.3758/s13415-013-0173-7

Schröger, E. (1996). A neural mechanism for involuntary attention shifts to changes in auditory stimulation. Journal of Cognitive Neuroscience, 8(6), 527-539. https://doi.org/10.1162/jocn.1996.8.6.527

Schröger, E., Bendixen, A., Trujillo-Barreto, N. J., \& Roeber, U. (2007). Processing of Abstract Rule Violations in Audition. Plos One, 2(11). https://doi.org/10.1371/journal.pone.0001131

Schröger, E., Giard, M. H., \& Wolff, C. (2000). Auditory distraction: Event-related potential and behavioral indices. Clinical Neurophysiology, 111(8), 1450-1460. https://doi.org/10.1016/S13882457(00)00337-0

Schröger, E., Marzecová, A., \& SanMiguel, I. (2015). Attention and prediction in human audition: A lesson from cognitive psychophysiology. European Journal of Neuroscience, 41(5), 641-664. https://doi.org/10.1111/ejn.12816

Schröger, E., \& Wolff, C. (1998). Behavioral and electrophysiological effects of task-irrelevant sound change: a new distraction paradigm. Cognitive Brain Research, 7(1), 71-87. https://doi.org/10.1016/s0926-6410(98)00013-5

Shtyrov, Y., Hauk, O., \& Pulvermuller, F. (2004). Distributed neuronal networks for encoding 
category-specific semantic information: the mismatch negativity to action words. European Journal of Neuroscience, 19(4), 1083-1092. https://doi.org/10.1111/j.1460-9568.2004.03126.x

Sussman, E., Winkler, I., \& Schröger, E. (2003). Top-down control over involuntary attention switching in the auditory modality. Psychonomic Bulletin \& Review, 10(3), 630-637. https://doi.org/10.3758/bf03196525

Wessel, J. R. (2017). Perceptual surprise aides inhibitory motor control. Journal of Experimental Psychology: Human Perception and Performance, 43(9), 1585-1593. https://doi.org/10.1037/xhp0000452

Wessel, J. R., \& Aron, A. R. (2013). Unexpected Events Induce Motor Slowing via a Brain Mechanism for Action-Stopping with Global Suppressive Effects. Journal of Neuroscience, 33(47), 18481-18491. https://doi.org/10.1523/jneurosci.3456-13.2013

Wessel, J. R., Danielmeier, C., Morton, J. B., \& Ullsperger, M. (2012). Surprise and Error: Common Neuronal Architecture for the Processing of Errors and Novelty. Journal of Neuroscience, 32(22), 7528-7537. https://doi.org/10.1523/JNEUROSCI.6352-11.2012

Wessel, J. R., Jenkinson, N., Brittain, J. S., Voets, S. H. E. M., Aziz, T. Z., \& Aron, A. R. (2016). Surprise disrupts cognition via a fronto-basal ganglia suppressive mechanism. Nature Communications, 7 , 1-10. https://doi.org/10.1038/ncomms11195

Wetzel, N., Widmann, A., \& Schröger, E. (2011). Processing of novel identifiability and duration in children and adults. Biological Psychology, 86(1), 39-49.

https://doi.org/10.1016/j.biopsycho.2010.10.005 


\section{Acknowledgments}

Fabrice Parmentier and Pilar Andrés, Department of Psychology, University of the Balearic Islands, Spain. Martin Vasilev, Department of Psychology, Bournemouth University. Fabrice Parmentier is also an Adjunct Senior Lecturer at the School of Psychology, University of Western Australia. This work was supported by research grants from the Spanish Ministry of Science, Innovation and Universities (PSI2014-54261-P \& PSI2016-75484-R) awarded to Fabrice Parmentier and Pilar Andrés respectively. Fabrice Parmentier's contract at the University of the Balearic Islands is co-financed by the Spanish Ministry of Science, Innovation and Universities through their program for the incentivization and permanent incorporation of doctors (2016's call, Ref. IEDI-2016-00742). This work was presented as a poster at the $25^{\text {th }}$ Annual Convention of the Association for Psychological Science, Washington, 23-26 May 2013, and as an oral presentation at the $18^{\text {th }}$ Meeting of the European Society for Cognitive Psychology, Budapest, August 29 - September 1, 2013. The data presented in this study are available upon request to the first author (fabrice.parmentier@uib.es). 
Table 1

\begin{tabular}{|c|c|c|c|c|c|}
\hline \multicolumn{6}{|c|}{ Response times } \\
\hline Effect & $\mathrm{b}$ & SE & $\mathrm{t}$ & $95 \%$ & $95 \%$ \\
\hline & & & & Lower & Upper \\
\hline Intercept & 537.267 & 6.808 & 78.910 & 523.923 & 550.611 \\
\hline Surprise & 125.595 & 18.475 & 6.800 & 89.385 & 161.806 \\
\hline \multicolumn{6}{|c|}{ Proportion Correct } \\
\hline Effect & $\mathrm{b}$ & SE & $\mathrm{t}$ & $95 \%$ & $95 \%$ \\
\hline & & & & Lower & Upper \\
\hline Intercept & .888 & .0114 & 77.850 & .866 & .911 \\
\hline Surprise & -.157 & .035 & -4.450 & -.227 & -.088 \\
\hline
\end{tabular}

Table 1. Results from the LMMs for response times and the proportion of correct responses. Statistically significant $t$-values are highlighted in bold. 
Table 2

\begin{tabular}{|c|c|c|c|c|c|c|}
\hline \multicolumn{7}{|c|}{ Response Times } \\
\hline Model 1 predictors & $\mathrm{R}^{2}$ of Model 1 & Model 2 & $\mathrm{R}^{2}$ of Model 2 & Change in $\mathrm{R}^{2}$ & $\mathrm{~F}(1,389)$ & $\mathrm{p}$ \\
\hline Surprise & .949 & +2 -factorial model & .949 & .000 & 0.323 & .570 \\
\hline 2-factorial model & .914 & +Surprise & .949 & .035 & 266.926 & $<.001$ \\
\hline \multicolumn{7}{|c|}{ Proportion Correct } \\
\hline Model 1 predictors & $\mathrm{R}^{2}$ of Model 1 & Model 2 & $\mathrm{R}^{2}$ of Model 2 & Change in $\mathrm{R}^{2}$ & $\mathrm{~F}(1,389)$ & $\mathrm{p}$ \\
\hline Surprise & .883 & +2-factorial model & .888 & .005 & 17.005 & $<.001$ \\
\hline 2-factorial model & .738 & +Surprise & .888 & .150 & 522.265 & $<.001$ \\
\hline
\end{tabular}

Table 2. Results of the regression analyses comparing single (Model 1) and two-predictor (Model 2) models. The change in $\mathrm{R}^{2}$ reflects the unique variance accounted for by the predictor added in Model 2. Statistically significant changes in $\mathrm{R}^{2}$ are highlighted in bold. For response times, the proportion of variance uniquely explained by the Surprise model was significant, whereas that of the 2-factorial model was not. For response accuracy, both models contributed significantly, but the proportion of variance uniquely explained by the Surprise model was larger than that explained by the 2-factorial model (changes in $\mathrm{R}^{2}$ of .150 and .005 , respectively). 


\section{Figure captions}

Figure 1. Mean response times (left) and mean response accuracy (right) as a function of the type of sound trial and whether the response on the previous trial was correct or an error. Error bars represents 95\% CIs calculated for the interaction term following Jarmasz \& Holland (2009).

Figure 2. Surprise as a function of the type of sound trial and whether the response to the previous trial was correct or an error. Error bars represents 95\% CIs calculated for the interaction term following Jarmasz \& Holland (2009).

Figure 3. Observed versus fitted response times (left) and proportions of correct responses (right) for the Surprise and 2-factorial models (corresponding to Model 1 in Table 2). The predicted values for each model were generated using the linear mixed models described in the text.

Figure A1. Observed versus fitted response times (left) and proportions of correct responses (right) for the Surprise and 2-factorial models (corresponding to Model 1 in Table A1). The predicted values for each model were generated after exclusion of extreme observed data points. 
Figure 1
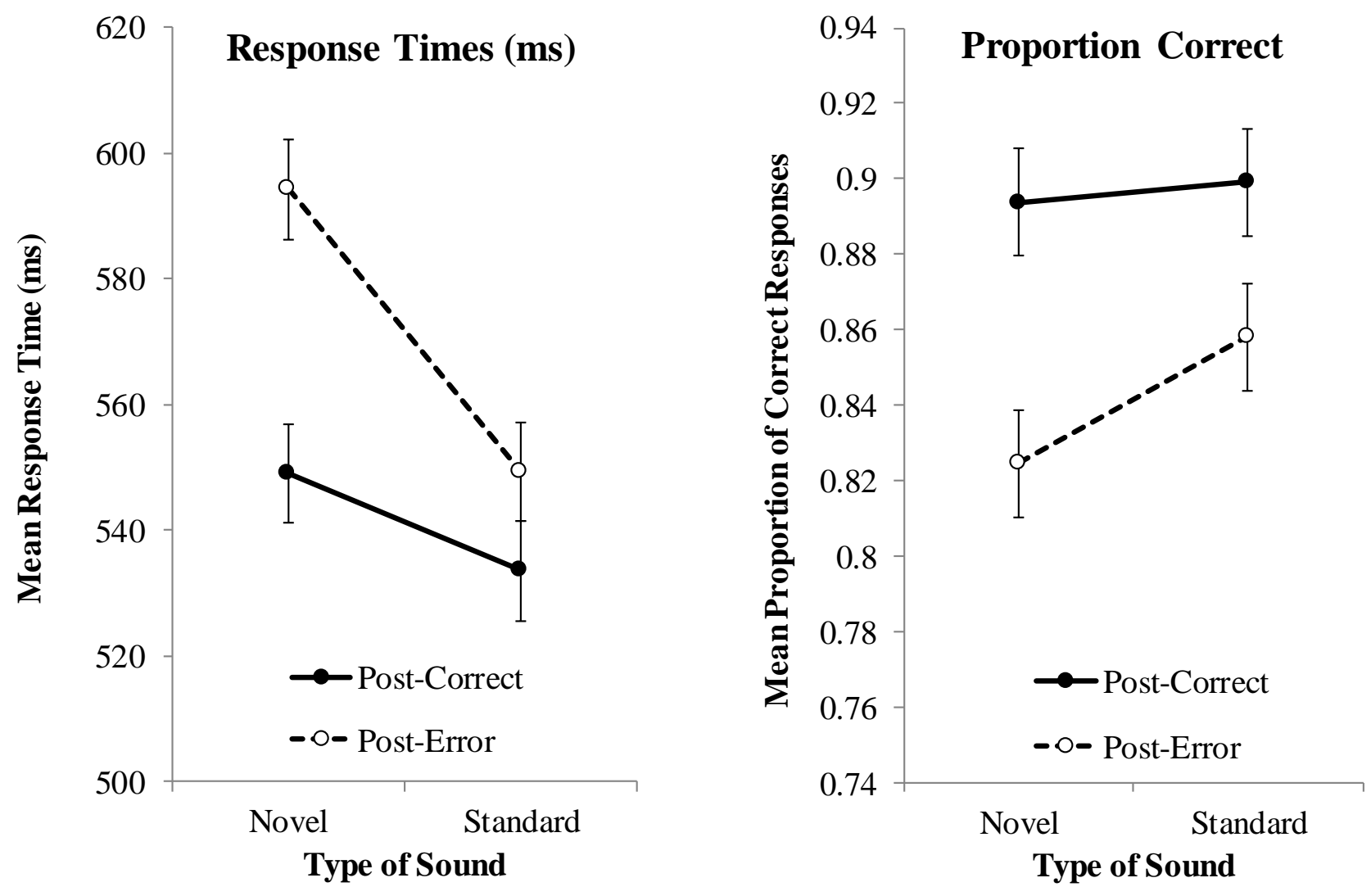
Figure 2

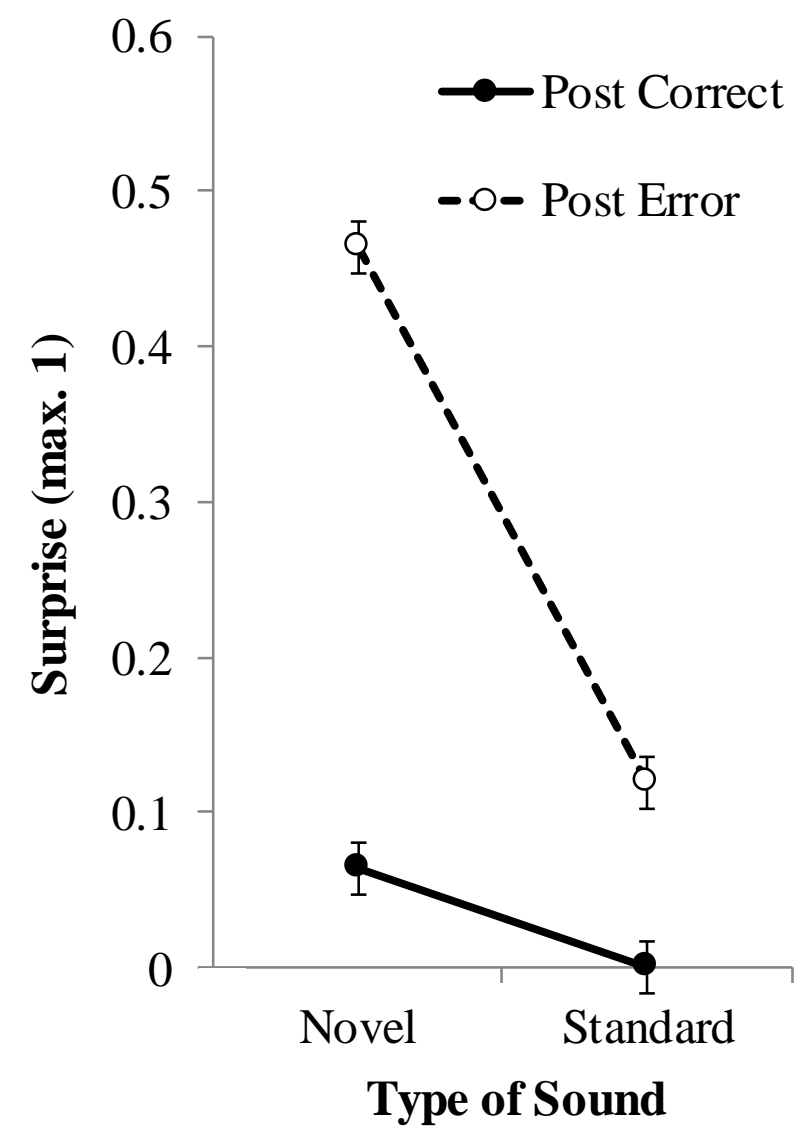




\section{Response Time (ms)}

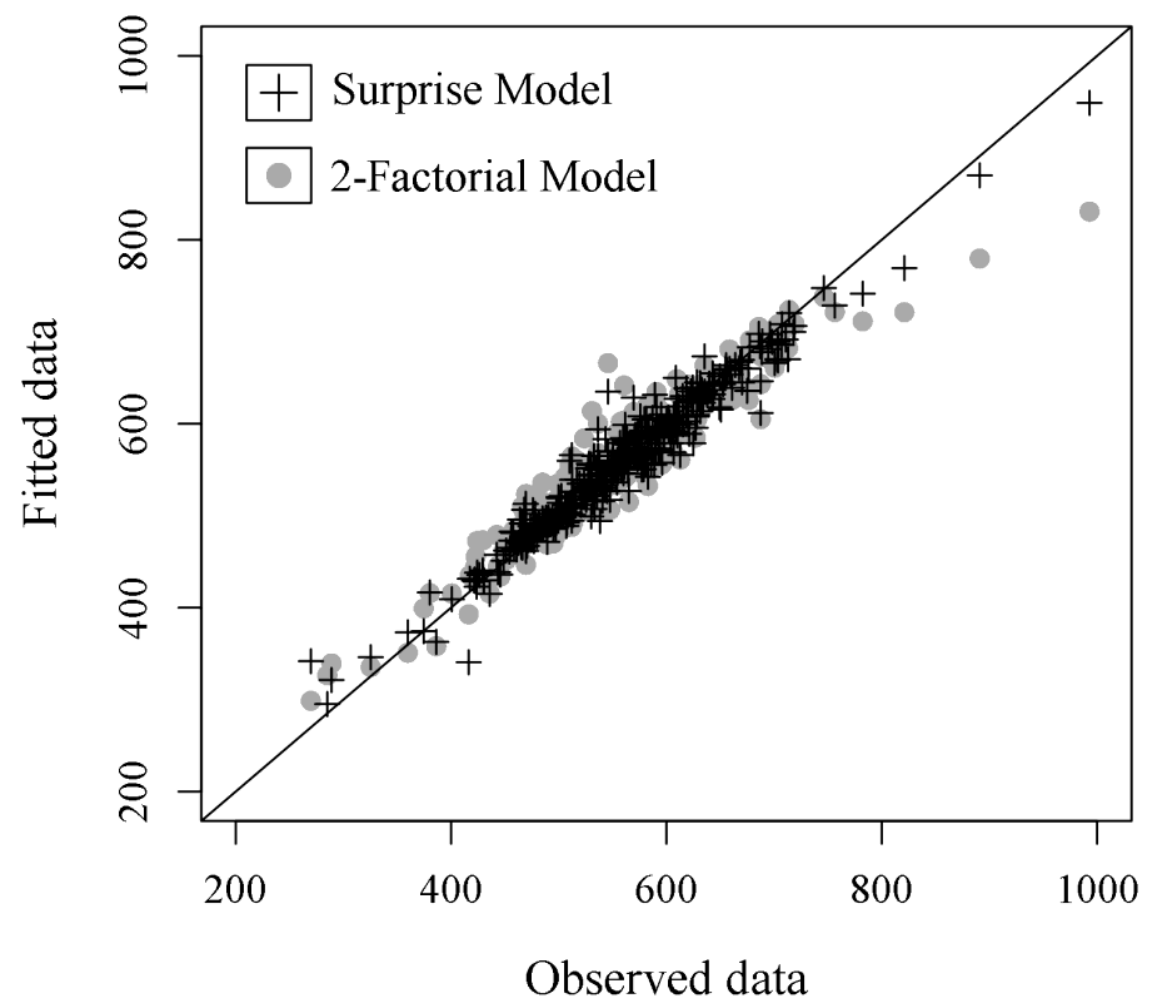

\section{Proportion Correct}

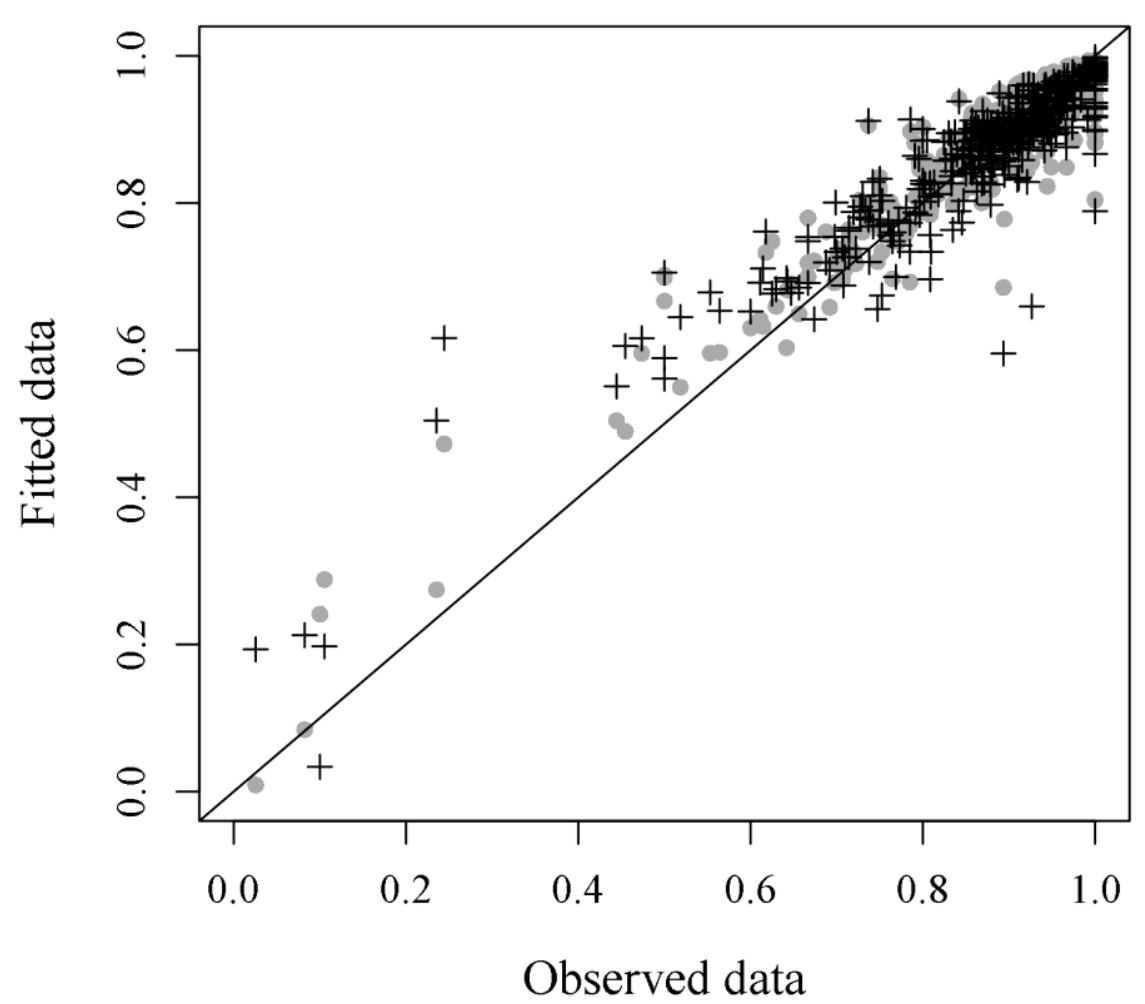




\section{Response Time (ms)}

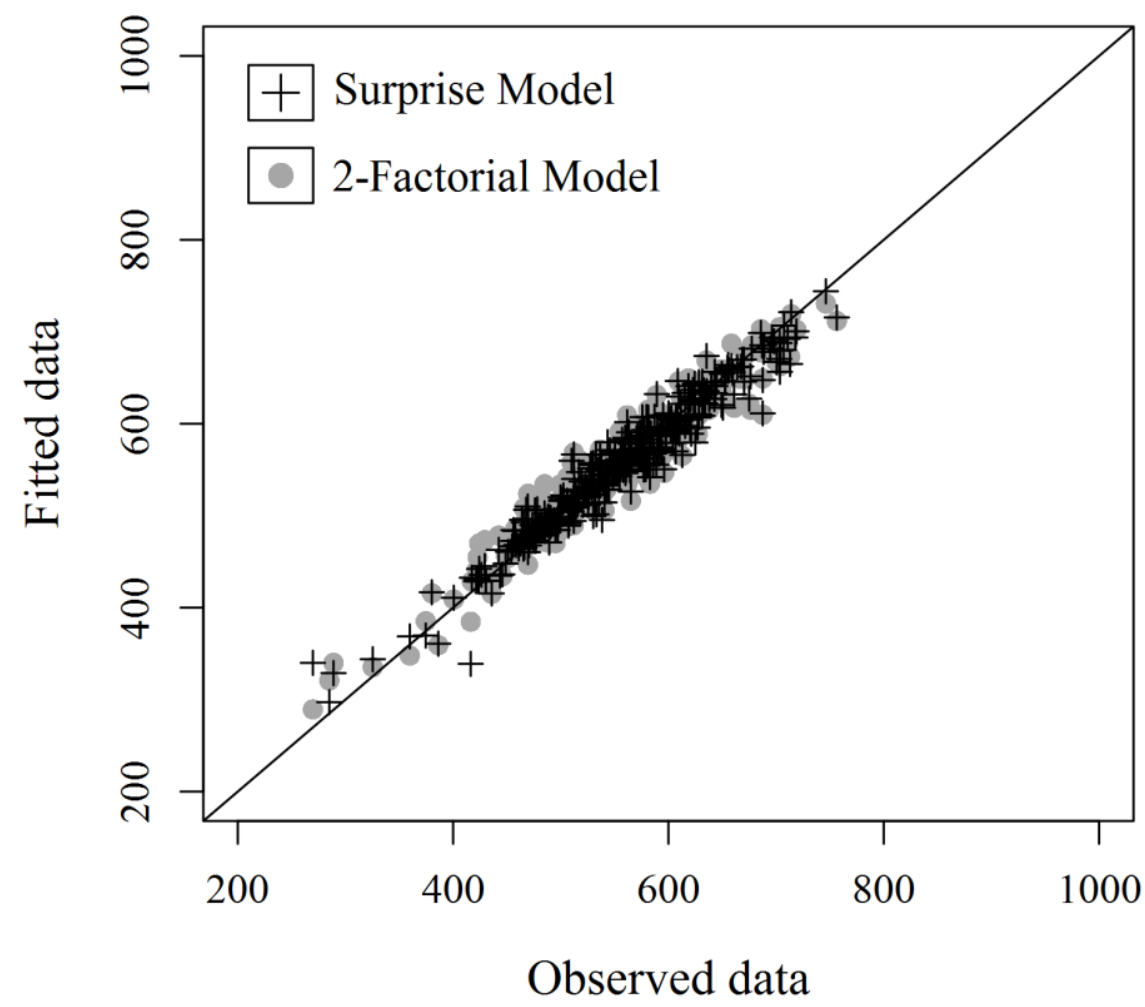

\section{Proportion Correct}

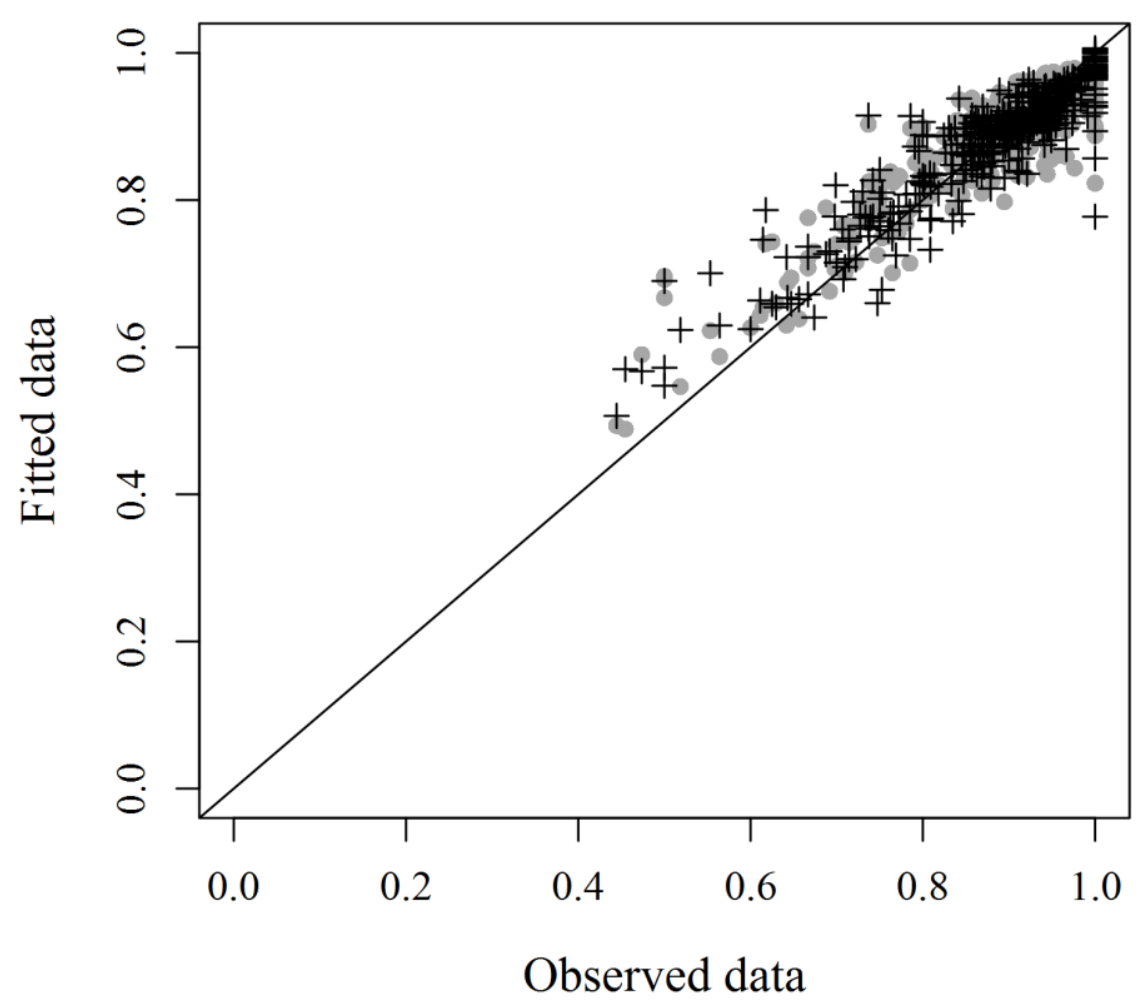




\section{Appendix}

\section{Comparison of the Surprise and 2-factorial models after exclusion of some data points}

The fitted data for RTs and the proportion of correct responses were obtained using Linear Mixed Models (LMMs) as described in the text. The only difference was that the four longest observed RTs and the six lowest observed proportions of correct responses (identified visually as departing from the rest of the data points in Figure 3) were removed from the data prior to fitting the models. The comparisons of the proportions of variance of the observed data explained by the Surprise and 2factorial models are presented in Table A1. While the proportion of variance explained by the Surprise model was numerically greater than the proportion of variance explained by the 2-factorial model (see the $\mathrm{R}^{2}$ value for Model 1 in Table A1), both models fitted the empirical data well (see Figure A1), and both models accounted for a unique proportion of variance (see the change in $\mathrm{R}^{2}$ in Table A1).

\begin{tabular}{|c|c|c|c|c|c|c|}
\hline \multicolumn{7}{|c|}{ Response Times } \\
\hline Model 1 predictors & $\mathrm{R}^{2}$ of Model 1 & Model 2 & $\mathrm{R}^{2}$ of Model 2 & Change in $\mathrm{R}^{2}$ & $\mathrm{~F}(1,385)$ & $p$ \\
\hline Surprise & .944 & +2 -factorial model & .946 & .002 & 16.225 & $<.001$ \\
\hline 2-factorial model & .938 & +Surprise & .946 & .009 & 123.972 & $<.001$ \\
\hline \multicolumn{7}{|c|}{ Proportion Correct } \\
\hline Model 1 predictors & $\mathrm{R}^{2}$ of Model 1 & Model 2 & $\mathrm{R}^{2}$ of Model 2 & Change in $\mathrm{R}^{2}$ & $F(1,383)$ & $\mathrm{p}$ \\
\hline Surprise & .849 & +2 -factorial model & .857 & .009 & 23.452 & $<.001$ \\
\hline 2-factorial model & .813 & +Surprise & .857 & .044 & 117.999 & $<.001$ \\
\hline
\end{tabular}


Table A1. Results of the regression analyses comparing single (Model 1) and two-predictor (Model 2) models using the reduced data set. The change in $\mathrm{R}^{2}$ reflects the unique variance accounted for by the predictor added in Model 2. Statistically significant changes in $\mathrm{R}^{2}$ are highlighted in bold.

- - - Insert Figure A1 about here - - - 